\title{
Socio-economic indicators and predisposing factors associated with traumatic dental injuries in schoolchildren at Brasília, Brazil: a cross-sectional, population-based study
}

\author{
Maria de Lourdes Vieira Frujeri ${ }^{1 *}$, José Angelo Junqueira Frujeri ${ }^{1}$, Ana Cristina Barreto Bezerra', \\ Maria IIma de Souza Gruppioni Cortes ${ }^{2}$ and Edson Dias Costa Jr ${ }^{1}$
}

\begin{abstract}
Background: This study assessed the prevalence of traumatic dental injuries (TDI) and its association with sociodemographic and physical characteristics in the anterior permanent teeth of 12-year-old schoolchildren at the city of Brasília - DF, Brazil.

Methods: A cross-sectional, population-based study was conducted on a sample of 1,389 boys and girls aged 12 years, enrolled in public and private fundamental schools at the Administrative Region (RA) of Brasília, Brazil, from October 2011 to September 2012. The demographic details were achieved by a structured questionnaire. The study recorded the type of damage, the size of incisal overjet, and whether lip coverage was inadequate. Sociodemographic data included sex, income and educational level of the parents or caretakers.

Results: A total of 1118 schoolchildren were examined, yielding a response rate of $80.48 \%$. The prevalence of TDI was $14.63 \%$ in public schools and $23.40 \%$ in private schools. The students did not differ according to sex, income and educational level of the parents or caretakers concerning the occurrence of traumas in permanent anterior teeth. Increased overjet and inadequate lip coverage were found to be important contributing factors for TDIs.
\end{abstract}

Conclusion: In conclusion, this study showed an expressive prevalence of TDI in 12-year-old in schoolchildren at Brasília DF, Brazil. Sex and educational level of the parents were not associated with trauma. The increased overjet and inadequate lip coverage were significantly associated with dental trauma.

Keywords: Tooth injuries, Prevalence, Demographic data

\section{Background}

Traumatic dental injuries (TDI) have been extensively studied over the last few decades. They result in tooth fracture, displacement or loss, causing negative functional, esthetic and psychological effects to the individuals (children, adolescents and adults) [1-3]. Previous studies reported prevalence rates ranging from $6 \%$ to $27 \%$ in different populations [4-10]. In Brazil the prevalence varies widely, ranging from $10 \%$ to $58 \%$ [11-16]. The possible explanations

\footnotetext{
* Correspondence: frujeri@terra.com.br

'Department of Dentistry, University of Brasília (UnB), AEC Setor G Norte Edifício Taguacenter Sala 116, Taguatinga, Braślia, DF, Brazil

Full list of author information is available at the end of the article
}

for this variation include differences in places/environments, diagnostic criteria and examination methods [17].

Etiology and predisposing factors of traumatic injuries are well established in the literature. However, impact of socio-economic indicators remains conflicting and unclear $[18,19]$. The increased violence rates, number of car accidents and greater participation of children in sports activities contribute to make dental trauma an emerging public health problem. Also, the greater availability and access of leisure devices with potential risk have remarkably increased the number of cases [15]. Glendor [20] conducted a literature review on the etiology and reported risk factors for traumatic dental injuries and concluded that the number of causes of TDIs have alarmingly increased over the 
last decades. The author suggested that this phenomenon may be associated to the increased interest on the causes and also evidences the complex etiology of TDIs. The investigator also concluded that not only risk factors as overjet and inadequate lip coverage contribute to increase the TDIs, but also the complex interaction between the oral status of the patient, design of public parks and school playgrounds and human behavior. The question is to what extent these factors, together or separately, influence the risk of TDI.

Studies have consistently shown that male individuals have a higher chance of TDI than female individuals $[8,10,17]$. Socio-economic status has been associated with several oral diseases and conditions, such as dental caries, periodontal diseases, tooth loss, and oral cancer. Nevertheless, the association between TDI and socio-economic indicators remains unclear [14,21,22]. Although some researchers have reported that schoolchildren with lower socio-economic status are more likely to suffer TDI $[2,13,14,17,19]$, others have shown an inverse correlation, with wealthier children having a higher risk of TDI $[9,13]$. A review paper concluded that there are few studies correlating TDI in permanent teeth with socio-economic indicators and that the majority did not find such association [22].

Among the physical factors, increased overjet and inadequate lip has been consistently associated with TDI $[12,13,19,21,23]$. A systematic review using meta-analysis stated that an overjet greater than $3 \mathrm{~mm}$ increases the chance of dental trauma. Other study considered that inadequate lip coverage is a more important risk factor for the occurrence of TDI than the increased overjet separately [24].

The purpose of this study was to assess the prevalence of TDI and its association with sociodemographic and physical characteristics in anterior permanent teeth of 12year-old schoolchildren at the city of Brasília - DF, Brazil.

\section{Subjects and methods}

This study was approved by the Institutional Review Board of the Health Sciences School at the University of Brasília, DF, Brazil. The Education Secretariat of the Government of Distrito Federal (GDF) authorized the study and provided the necessary information for the sample registry, which was updated on the examination date. The following data were obtained: name of all schools at Brasília, their addresses and total number of students registered in each school, at the age of 12 years.

A cross-sectional, population-based study was conducted on a sample of 1389 boys and girls aged 12 years, enrolled at public and private fundamental schools at the Administrative Region (RA) of Brasília, Brazil.

The sample size was calculated based on a sample error of $1.7 \%$, significance level of $5 \%$, prevalence of dental injuries of $20 \%$ and a population of 4,000 students aged 12 years, registered in public and private schools at Brasília, according to the school census of 2011.

The total of 83 fundamental schools at the administrative region of Brasília, being 43 public and 40 private, were initially contacted on the interest to participate in the study. Only one public school did not agree to participate, while only 23 private schools agreed to participate.

A letter was sent to all parents or caretakers of the selected children explaining the objectives, characteristics and importance of the study. Within each school, the study was conducted only on children whose parents or caretakers signed the consent form. The final sample was composed of 787 students of public schools and 658 students of private schools, among which, in 1,118 children, it was possible to obtain information on the variables analyzed, yielding a response rate of $80.45 \%$, based on the planned sample (Figure 1).

Socio-demographic data included the type of school (public or private), sex and educational level of the caretaker in completed years of study. The socio-economic data on the caretakers were collected by a questionnaire previously applied in another epidemiological survey [25]. This socio-economic questionnaire was used during the last Brazilian Oral Health Survey and a prevalence of $20.5 \%$ of traumatic dental injuries was found. This questionnaire was divided into four parts. The first part comprised the identification data. Similarly, in this study, we confirmed the student's identification data, race, sex, birth date, and educational level of the parents/caretakers. The second part was composed by data on the socio-economic characteristics of the family: number of persons living in the house; number of bedrooms; material goods (TV, refrigerator, stereo, microwave oven, washing machine, number of cars; ranging from zero to ten goods); and also the family income (the sum of incomes received per each person living in the house ranging from $\mathrm{R} \$ 250.00$ to 9,500.00). The third part comprised questions on the educational level and years of the parents, oral morbidity and use of oral health services. And finally, the fourth part contained three questions on oral health self-perception and impacts of the parents. A section containing questions on the TDI was added to this questionnaire. TDI questions aimed to gather information on the self-perception of the parents relating to tooth traumas (first-aid notions in cases of tooth traumas, occurrence of accidents involving the mouth/teeth inside the family). If tooth trauma within the family was positively reported, we investigated which dentition was involved (primary or permanent); which type of traumatism occurred; and whether immediate care was provided. This form was sent to parents who agreed to participate in the study before clinical examination of the children "See Additional file 1." The clinical forms and questionnaires were previously tested and did not require adjustments. A pilot study was conducted on thirty 


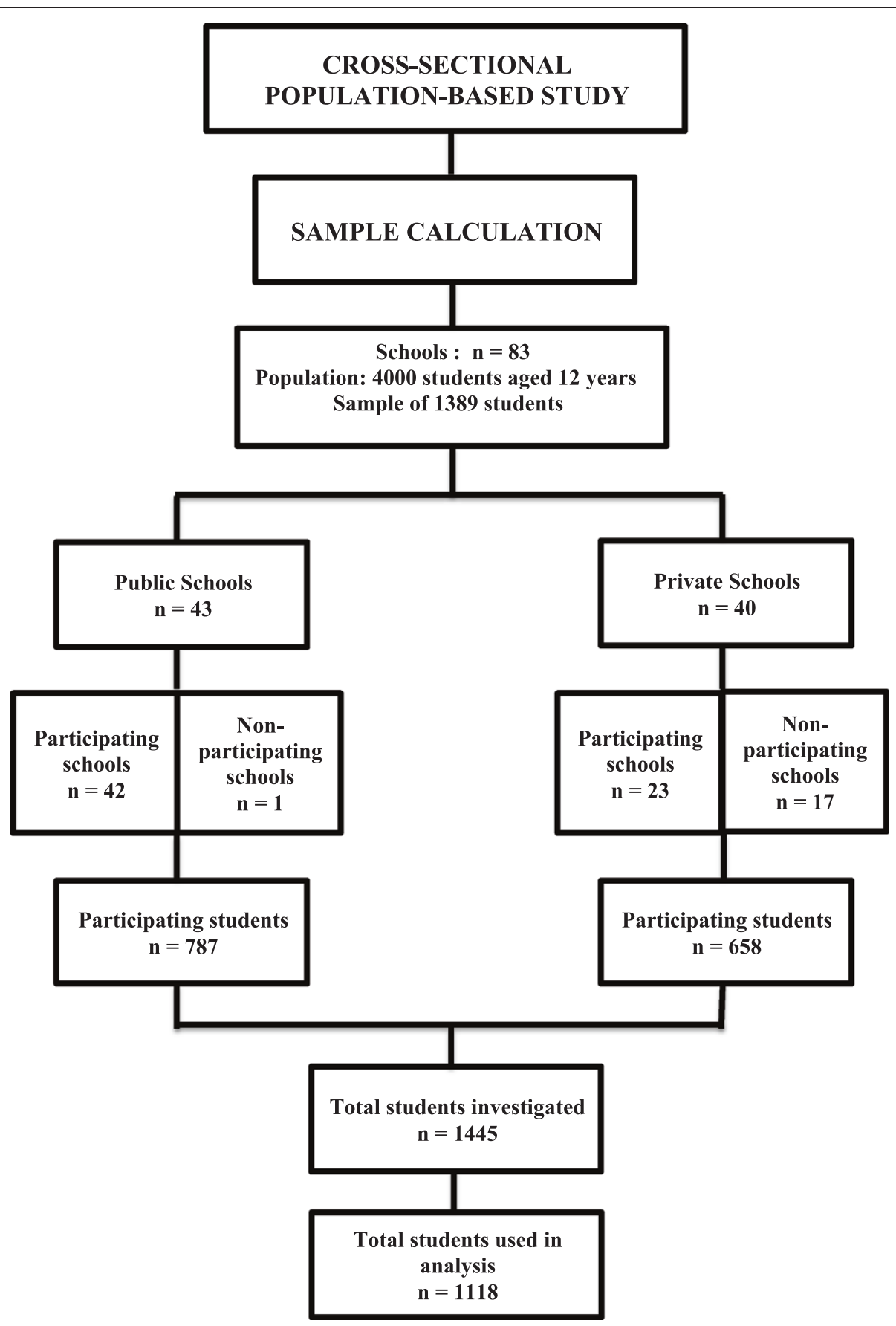

Figure 1 Sample calculation and response rate of the study. Brasilia, DF, 2012.

parents of the same sample to test the questionnaire. The results revealed that it was feasible in the local situation. The first thirty socio-economic questionnaires were used to test the research instrument adapted for this present study. The instrument was well understood by the participants and it was considered as effective for data collection. Thus, no adjustments were necessary. These questionnaires were included in the general sample.
Clinical data on dental trauma, lip coverage and incisal overjet were collected by oral examinations. The etiology, site of occurrence of dental trauma, age at the occurrence of trauma were obtained by direct interview with the child. The criteria for classification of trauma were the same used in the Children's Dental Health Survey at the United Kingdom [26]. These criteria include tooth fractures, discoloration and loss due to trauma to the permanent 
dentition. The incisal overjet was coded as smaller or equal to $5 \mathrm{~mm}$ or greater than $5 \mathrm{~mm}$., after measurement of the greatest distance between the incisal edges of maxillary incisors in relation to the incisal edges of corresponding mandibular teeth using a CPI periodontal probe. The anterior maxillary overjet was measured with the mandibular and maxillary teeth at centric occlusion with the aid of a CPI periodontal probe placed parallel to the occlusal plane. The overjet is the greatest distance in $\mathrm{mm}$ between the incisal edges of maxillary incisors in relation to the incisal edges of corresponding mandibular incisors.

Anterior mandibular overjet is characterized by the anterior (labially) position of the mandibular incisors in relation to the corresponding maxillary incisors. Mandibular protrusion or crossbite was measured with the aid of a CPI periodontal probe and recorded in millimeters. Vertical open bite was characterized by lack of overlapping between maxillary and mandibular incisors.

During data collection on lip coverage, it was considered as adequate when the lips touched, entirely covering the anterior teeth, with the schoolchildren silently reading a document without knowing they were being observed. Data were collected by two dentists (Frujeri MLV and Frujeri JAJ) with help of two annotators, previously trained and calibrated at the Center of Trauma a the Federal University of Minas Gerais (UFMG). The calibration/training exercises were conducted by the professors in charge of the Center of Trauma at the aforementioned university using photographs and images of different types of traumas and patients suffering dentoalveolar traumas assisted at the clinics of this center. The degree of diagnostic reproducibility was high, the kappa coefficients for inter-examiner agreement ranged from 0.85 to 1.00 , indicating almost perfect to perfect agreement, since in most cases the kappa value was equal to one.The kappa coefficients for intra-examiner agreement were all equal to 1.00 , indicating perfect agreement for both examiners.

The clinical examinations were performed at the schools, during the classes, in open areas with enough natural light, with the children seated on chairs. All biosecurity procedures were strictly followed. Dental mirrors, CPI periodontal probes and gauze were packed and sterilized in sufficient numbers for one day of work. The examination included all permanent anterior teeth (incisors and canines). All teeth were dried before examination to increase the accuracy of the diagnosis. The examiner assessed existence and type of damage, treatment carried out, whether the incisal overjet was smaller or equal to $5 \mathrm{~mm}$ or greater than $5 \mathrm{~mm}$ and whether lip coverage was inadequate. The examination was conducted in a uniform fashion beginning from the maxillary right quadrant to the mandibular in clockwise direction. When the child was absent on the day of examination, a second visit was done. When tooth trauma presence was verified through clinical examination, the following characteristics were recorded into a specific sheet: type and site of injury; etiology; teeth damaged. Also, tooth trauma treatment and material type was recorded. It was recorded whether the teeth undergone trauma had not been treated until the moment of the research "See Additional file 2". In these cases, the parents/ caregivers were instructed on the importance of both trauma treatment and following-up through a letter. A pilot study was conducted on thirty schoolchildren of the same sample to test the methodology. The results revealed that it was feasible in the local situation. The inter- and intra-examiner diagnostic variability was assessed by examination in duplicate in $10 \%$ of the sample. The Kappa statistics was applied considering each tooth in each situation analyzed. These students were included in the total sample of 1,118 participants used in the analysis.

Data were entered and analyzed on the software SAS 9.2 for Windows. To evaluate if the type of overjet, lip coverage, location of the school, sex, income and educational level might explain the occurrence of trauma in permanent teeth, a mixed-effects multiple logistic regression model, with random intercept [27] was used to compensate the intra-school correlation, since the schoolchildren are clustered within schools. As a result of the model adjustment, the odds ratio and respective $95 \%$ confidence intervals were calculated.

\section{Results}

The prevalence of dental trauma according to the variables analyzed is presented in Table 1.

The multivariate analysis results are in Table 2 .

The results of association studies demonstrated that students in private and public schools may have differed as to the occurrence of traumas in permanent teeth $[\mathrm{OR}=1.53$; CI 95\%: 0.99-2.38; p-value $=0.05]$. Concerning the gender, they did not differ regarding the occurrence of traumas in permanent teeth [OR $=1.33$; CI 95\%: $0.96-1.85]$. The income and educational level did not differ concerning the occurrence of traumas in permanent teeth $(\mathrm{p}=0.65$ and $\mathrm{p}=0.49$, respectively). It was observed that students with inadequate lip coverage had 8.94 times more chances of having trauma to permanent teeth than those with adequate lip coverage $[\mathrm{OR}=8.94$; CI 95\%: 5.92-13.51; p-value < 0.0001].

It was also observed that students with overjet in the anterior maxilla had 2.98 times more chances of having trauma to permanent tooth than those with open bite $[\mathrm{OR}=2.98$; CI 95\%: 1.15-7.93; p-value $=0.04]$. Even though the confidence interval had the value 1 , it is strongly asymmetric to the right and suggests that the association for this category of overjet with trauma to permanent tooth is considerable. Thus, students with overjet in the anterior mandible had 6,43 times more chances of having trauma to permanent tooth than those with open bite $[\mathrm{OR}=6.43$; IC 95\%: 1.02-30.54; p-value $=0.04$ ]. 
Table 1 Prevalence of trauma to permanent teeth according to the variables analyzed in 12-year-old schoolchildren at the city of Brasília- DF- Brazil, in the year 2012

\begin{tabular}{|c|c|c|c|}
\hline Variables & $\begin{array}{l}\text { Frequency } \\
(n=1118)\end{array}$ & $\begin{array}{l}\text { Prevalence of } \\
\text { trauma to } \\
\text { permanent teeth (\%) }\end{array}$ & ${ }^{*} \mathrm{Cl} 95 \%$ \\
\hline \multicolumn{4}{|l|}{ School } \\
\hline Public & 588 & 14.63 & $11.76-17.49$ \\
\hline Private & 530 & 23.40 & $19.79-27.01$ \\
\hline \multicolumn{4}{|l|}{ Lip coverage } \\
\hline Adequate & 989 & 13.65 & $11.51-15.79$ \\
\hline Inadequate & 129 & 58.14 & $49.61-66.67$ \\
\hline \multicolumn{4}{|l|}{ Overjet } \\
\hline Anterior maxilla & 1064 & 18.89 & $16.53-21.25$ \\
\hline Anterior mandible & 11 & 27.27 & $0.91-53.63$ \\
\hline Open bite & 43 & 13.95 & $3.58-24.33$ \\
\hline \multicolumn{4}{|l|}{ Sex } \\
\hline Male & 536 & 21.27 & $17.80-24.74$ \\
\hline Female & 582 & 16.49 & $13.47-19.51$ \\
\hline \multicolumn{4}{|l|}{ Educational level } \\
\hline Fundamental & 210 & 12.86 & $8.32-17.39$ \\
\hline High school & 306 & 18.30 & $13.96-22.64$ \\
\hline Graduation & 494 & 20.44 & $16.88-24.01$ \\
\hline Postgraduate & 108 & 24.07 & $16.00-32.15$ \\
\hline \multicolumn{4}{|l|}{ Income (real) } \\
\hline Up to 250 & 13 & 15.38 & $0.00-35.03$ \\
\hline $251-500$ & 67 & 11.94 & $4.16-19.72$ \\
\hline $501-1500$ & 291 & 18.21 & $13.77-22.65$ \\
\hline $1501-2500$ & 141 & 17.73 & $11.42-24.04$ \\
\hline $2501-4500$ & 143 & 16.09 & $10.05-22.11$ \\
\hline $4501-9500$ & 206 & 21.36 & $15.75-26.96$ \\
\hline$>9500$ & 257 & 21.40 & $16.38-26.42$ \\
\hline
\end{tabular}

\section{Discussion}

The good response rate, calibration process and intra- and inter-examiner reproducibility data collaborated to the interval validity of data. The prevalence of dental trauma in the sample analyzed at Brasília was $14.63 \%$ in public schools and $23.40 \%$ in private schools. This value is relatively high if compared to other studies involving the same type of population and age. Higher values were observed at Blumenau-SC (58.6\%) [19] and lower values were reported at the cities of Jaraguá do Sul -SC (15.3\%) [11], Belo Horizonte-MG (13.6\%) [12], Anápolis- GO (16,5\%) [16], Florianópolis -SC (18.9\%) [28], Campina Grande- PB (21\%) [29] Recife -PE (23.3\%) [13] and Herval d'Oeste SC (17.3\%) [15].

According to the literature, the male gender is at higher risk to TDI. Usually, boys are more active and perform
Table 2 Likelihood of TDIs according to the adjusted odds ratio by mixed-effects logistic regression

\begin{tabular}{|c|c|c|}
\hline Indicators & ${ }^{*} \mathrm{OR}[\mathrm{Cl}$ 95\%] & $\mathrm{p}$-value \\
\hline \multicolumn{3}{|l|}{ Sex } \\
\hline Male & $1.33[0.96-1.85]$ & 0.08 \\
\hline Female & 1.00 & - \\
\hline Income & & 0.65 \\
\hline Up to 250 & 1.00 & - \\
\hline $251-500$ & $1.41[0.23-8.76]$ & 0.71 \\
\hline $501-1500$ & $2.11[0.39-11.29]$ & 0.38 \\
\hline $1501-2500$ & $1.52[0.28-8.39]$ & 0.63 \\
\hline $2501-4500$ & $1.27[0.23-7.08]$ & 0.79 \\
\hline $4501-9500$ & $1.64[0.30-9.10]$ & 0.57 \\
\hline$>9500$ & $1.30[0,23-7.28]$ & 0.76 \\
\hline Educational level & & 0.49 \\
\hline Fundamental & 1.00 & \\
\hline High school & $1.46[0.86-2.50]$ & 0.16 \\
\hline Graduation & $1.37[0.73-2.57]$ & 0.33 \\
\hline Postgraduate & $1.62[0.73-3.61]$ & 0.23 \\
\hline \multicolumn{3}{|l|}{ Location } \\
\hline Private & $1.53[0.99-2.38]$ & 0.05 \\
\hline Public & 1.00 & - \\
\hline \multicolumn{3}{|l|}{ Lip coverage } \\
\hline Inadequate & $8.94[5.92-13.51]$ & $<0.0001$ \\
\hline Adequate & 1.00 & - \\
\hline Overjet & & 0.05 \\
\hline Anterior maxilla & $2.98[1.15-7.93]$ & 0.04 \\
\hline Anterior mandible & $6.43[1.02-30.54]$ & 0.04 \\
\hline Open bite & 1.00 & - \\
\hline
\end{tabular}

*OR- Odds Ratio.

stronger physical activities as contact sports, fights, tougher plays and use toys and equipments with higher risk potential without adequate protection. In this study the prevalence in the male gender was higher than in females, yet this difference was not statistically significant $(\mathrm{p}=0.0850)$, being different from most published studies $[1,29]$. Some studies also did not report this difference $[13,15,30]$. According to a previous study, it is possible that, with the greater participation of girls in contact sports and plays, previously typical of boys, this difference might be reduced or even disappear [20].

The present results were equivocal about differences in the prevalence between children of public and private schools and also in relation to the income and educational level of the parents. Published data in the dental literature are conflicting.

Some demonstrate significant association between the prevalence and variables indicating better socio-economic condition [12,31], other corroborate the present study and 
did not report association [10,24], while other observed higher prevalence in children of lower socio-economic status $[13,30]$. There may be an interaction between the individual socio-economic condition and the physical environment. This is explained by the fact that a greater access to leisure goods and equipments may be associated to children with higher socio-economic level. For example, wealthier children have access to toys as bicycle, skate, horse riding, swimming pools and water skiing. Such equipments, when used without safety, may determine the increased prevalence. Conversely, less favored children are more exposed to public areas and recreation parks. Probably the individual mode of interaction with the environment determines the occurrence of dental trauma. Considering these inconclusive findings, further studies are necessary to elucidate the effect of the socioeconomic condition on the occurrence of dental trauma.

The relationship between overjet (OJ) and TDI has been investigated by different authors [11,15,32] and demonstrate that individuals with overjet greater than 5 $\mathrm{mm}$ are at higher risk to TDIs compared to those with normal overjet. This study corroborates these findings, since it evidenced significant association between the presence of TDI and overjet. It was observed that students with anterior maxillary overjet greater than or equal to $5 \mathrm{~mm}$ had 2.98 times more chances of having trauma to permanent teeth than those with open bite, and students with mandibular anterior overjet had 6.43 times more chance of trauma to permanent teeth than those with open bite. Other studies also demonstrated this relationship $[9,16]$. Therefore, it may be inferred that the increased overjet is an important risk factor to dental trauma [14,33,34].

Finally, concerning the inadequate lip coverage, this study revealed similar results as other published investigations $[19,35,36]$ that considered it as the most important and independent risk factor for the occurrence of TDIs in anterior teeth. Bonini et al. (2012) [35] observed that children with malocclusions as open bite and increased overjet, associated with inadequate lip coverage, presented high prevalence of TDIs compared to those with adequate lip coverage. It was also observed that malocclusions of anterior teeth (increased overjet and open bite) are significantly associated with TDIs only when inadequate lip coverage is present. The investigators observed that the presence of malocclusions with adequate lip coverage is not an important risk factor for TDIs. The findings of this study in the mixed-effects multiple logistic regression model corroborate the results of aforementioned investigations, since students with inadequate lip coverage had 8.94 times more chances of trauma to anterior teeth than those with adequate lip coverage (OR- CI 95\% [5.92-13.51] p-value < $0.0001)$. We share with these investigators the idea that this possibly occurs because the lips partly absorb the impact applied to the teeth during the trauma. Since these risk factors may be corrected by orthodontic treatment, the dental professionals should clinically diagnose these risk factors and inform the children's caretakers on the need of orthodontic intervention as early as possible [9].

\section{Conclusion}

Sex and educational level of the parents were not associated with trauma. The increased overjet and inadequate lip coverage were significantly associated with dental trauma.

\section{Additional files}

\section{Additional file 1: Socioeconomic form.}

Additional file 2: Interview and clinical examination of children participating in the survey on dental trauma.

\section{Competing interests}

The authors declare that they have no competing interests.

\section{Authors' contributions}

MLVF conceived of the study, participated in its design and coordination, carried out the population-based study and drafted the manuscript. JAJF participated in the design of the study, carried out the population-based study and performed the statistical analysis. ACBB participated in the design and coordination of the study as guiding the study. MISGC participated in the design of the study as co-advisor the study. EDCJ participated in the design of the study and helped to draft the manuscript. All authors read and approved the final manuscript.

\section{Acknowledgments}

The investigators would like to thank Professor Dr. Eduardo Freitas da Silva at the University of Brasília (UnB), DF, Brazil for his valuable help in the design, sample calculation and technical-operational conduct of the study and his constant presence throughout the statistical analysis.

The authors also thank Professors Drs. Maria IIma de Sousa G. Cortes and Juliana Vilela Bastos at the Federal University of Minas Gerais (UFMG), MG, Brazil for their careful and effective calibration of investigators.

\section{Author details}

${ }^{1}$ Department of Dentistry, University of Brasília (UnB), AEC Setor G Norte Edifício Taguacenter Sala 116, Taguatinga, Brasília, DF, Brazil. Department of Dentistry, University of Minas Gerais, Belo Horizonte, Brazil.

Received: 6 April 2014 Accepted: 10 July 2014

Published: 18 July 2014

\section{References}

1. Dua R, Sharma S: Prevalence, causes, and correlates of traumatic dental injuries among seven-to-twelve-year-old school children in Dera Bassi. Contemp Clin Dent 2012, 3:38-41.

2. Porritt JM, Rodd HD, Ruth Bake S: Quality of life impacts following childhood dento-alveolar trauma. Dent Traumatol 2011, 27:2-9.

3. Bendo CB, Paiva SM, Varni JW, Vale MP: Oral health-related quality of life and traumatic dental injuries in Brazilian adolescents. Community Dent Oral Epidemiol 2014, 42:216-223. 10.1111/cdoe.12078. Epub 2013 Oct 11.

4. Govindarajan M, Reddy VN, Ramalingam K, Durai KS, Rao PA, Prabhu A: Prevalence of traumatic dental injuries to the anterior teeth among three to thirteen-year-old school children of Tamilnadu. Contemp Clin Dent 2012, 3:164-167.

5. Altun C, Ozen B, Esenlik E, Guven G, Gurbuz T, Acikel C, Basak F, Akbulut E: Traumatic injuries to permanent teeth in Turkish children, Ankara. Dent Traumatol 2009, 25:309-313 
6. David J, Astrøm AN, Wang NJ: Factors associated with traumatic dental injuries among 12-year-old schoolchildren in South India. Dent Traumatol 2009, 25:500-505.

7. Navabazam A, Farahani SS: Prevalence of traumatic injuries to maxillary permanent teeth in 9- to 14-year-old school children in Yazd, Iran. Dent Traumatol 2010, 26:154-157.

8. Naidoo S, Sheiham A, Tsakos G: Traumatic dental injuries of permanent incisors in 11-to 13-year-old South African schoochildren. Dent Traumatol 2009, 25:224-228.

9. Borzabadi-Farahani A, Borzabadi-Farahani A: The association between orthodontic treatment need and maxillary incisor trauma, a retrospective clinical study. Oral Surg Oral Med Oral Pathol Oral Radiol Endod 2011, 112:e75-e80.

10. Locker D: Prevalence of traumatic dental injury in grade 8 children in six Ontario communities. Can J Public Health 2005, 96:73-76.

11. Marcenes W, Alessi ON, Traebert J: Causes and prevalence of traumatic injuries to the permanent incisors of schoolchildren aged 12 years in Jaragua do Sul, Brazil. Int Dent J 2000, 50:87-92.

12. Cortes Ml, Marcenes W, Sheiham A: Prevalence and correlates of traumatic injuries to the permanent teeth of schoolchilden aged 9-14 years in Belo Horizonte, Brazil. Dent Traumatol 2001, 17:22-26.

13. Soriano EP: Caldas- AF Jr, Goes PSA: Risk factors related to traumatic dental injuries in Brazilian schoolchildren. Dent Traumatol 2004, 20:246-250

14. Damé-Teixeira N, Alves LS, Susin C, Maltz M: Traumatic dental injury among 12-year-old South Brazilian schoolchildren: prevalence, severity, and risk indicators. Dent Traumatol 2013, 29:52-58.

15. Traebert J, Bittencourt DD, Peres KG, Peres MA, Lacerda JT, Marcenes W: Aetiology and rates of treatment of traumatic dental injuries among 12-year-old school children in a town in Southern Brazil. Dent Traumato 2006, 22:173-178.

16. Francisco SS, Filho FJ, Pinheiro ET: Murrer RD, de Jesus Soares A: Prevalence of traumatic dental injuries and associated factors among Brazilian schoolchildren. Oral Health Prev Dent 2013, 11:31-38. 10.3290/j.ohpd.a29373.

17. Patel MC, Sujan SG: The prevalence of traumatic dental injuries to permanent anterior teeth and its relation with predisposing risk factors among 8-13 years school children of Vadodara city: an epidemiological study. J Indian Soc Pedod Prev Dent 2012, 30:151-157.

18. Andreasen JO, Andreasen FM, Andersson L: Textbook and color atlas of traumatic injuries to the teeth. 4th edition. Oxford, UK: Ames, lowa: Blackwell Munksgaard; 2007

19. Marcenes W, Zabot NE, Traebert J: Socio-economic correlates of traumatic injuries to the permanent incisors in schoolchildren aged 12 years in Blumenau, Brazil. Dent Traumatol 2001, 17:222-226.

20. Glendor U: Aetiology and risk factors related to traumatic dental injuries - a review of the literature. Dent Traumatol 2009, 25:19-31.

21. Marcenes W, Murray S: Social deprivation and traumatic dental injuries among 14-year-old schoolchildren in Newham, London. Dent Traumatol 2001, 17:17-21.

22. Bendo CB, Scarpelli AC, Vale MP, Araujo Zarzar PM: Correlation between socioeconomic indicators and traumatic dental injuries: a qualitative critical literature review. Dent Traumatol 2009, 25:420-425.

23. Piovesan C, Abella C, Ardenghi M: Chid oral health-related quality of Life and Socioeconomic factors associated with traumatic dental injuries in schoolchildren. Oral Health Prev Dent 2011, 9:405-411.

24. Goettems ML, Torriani DD, Hallal PC, Correa MB, Demarco FF: Dental trauma: prevalence and risk factors in schoolchildren. Community Dent Oral Epidemio/ 2014, doi:10.1111/cdoe.12113. [Epub ahead of print] PubMed PMID: 24916889

25. SB Brasil; 2010 [http://dab.saude.gov.br/CNSB/sbbrasil/arquivos/ Ficha_Sb2010]

26. O'Brien M: Children's Dental Health in the United Kingdom 1993. In Report of Dental Survey. Office of Population Censuses and Surveys. London: Her Majesty's Stationery Office; 1994.

27. Hedeker D, Gibbons RD: Longitudinal Data Analysis. Chapter 9: Mixed-Effects Regression Models for Binary Outcomes. New York: John Wiley \& Sons; 2006:149-186

28. Traebert J, Peres MA, Balnk V, Boell R, Pietruza JÁ: Prevalence of traumatic dental injury and associated factors among 12-year old school children in Florianópolis, Brazil. Dent Traumatol 2003, 19:15-18.
29. Cavalcanti AL, Bezerra PKM, Alencar CRB, Moura C: Traumatic anterior dental injuries in 7-to12-year-old Brazilian children. Dent Traumatol 2009 25:198-202.

30. Traebert J, Almeida IC, Marcenes W: Etiology of traumatic dental injuries in 11 to 13-year-old schoolchildren. Oral Health Prev Dent 2003, 1:317-323.

31. Ramos-Jorge ML, Peres MA, Traebert J, Ghisi CZ, Paiva SM, Pordeus IA Marques LS: Incidence of dental trauma among adolescents: a prospective cohort study. Dent Traumatol 2008, 24:159-163.

32. Soriano EP, Caldas AF, Diniz De Carvalho MV, Amorim Filho HÁ: Prevalence and risk factors related to traumatic dental injuries in Brazilian schoolchildren. Dent Traumatol 2007, 23:232-240.

33. Schatz JP, Hakeberg M, Ostini E, Kiliaridis S: Prevalence of traumatic injuries to permanent dentition and its association with overjet in a Swiss child population. Dent Traumatol 2013, 29:110-114

34. Shalish M, Gal A, Brin L, Zini A, Ben-Bassat Y: Prevalence of dental features that indicate a need for early orthodontic treatment. Eur J Orthod 2012, 30:454-459.

35. Bonini G, Bönecker MB, Mendes FM: Combined effect of anterior malocclusion and inadequate lip coverage on dental trauma in primary teeth. Dent Traumatol 2012, 28:437-440.

36. Aldrigui JM, Jabbar NS, Bonecker M, Braga MM, Wanderley MT: Trends and associated factors in prevalence of dental trauma in Latin America and Caribbean: a systematic review and meta-analysis. Community Dent Oral Epidemiol 2014, 42:30-42. 10.1111/cdoe.12053. Epub 2013 May 3.

doi:10.1186/1472-6831-14-91

Cite this article as: Frujeri et al:: Socio-economic indicators and predisposing factors associated with traumatic dental injuries in schoolchildren at Brasília, Brazil: a cross-sectional, population-based study. BMC Oral Health 2014 14:91.

\section{Submit your next manuscript to BioMed Central and take full advantage of:}

- Convenient online submission

- Thorough peer review

- No space constraints or color figure charges

- Immediate publication on acceptance

- Inclusion in PubMed, CAS, Scopus and Google Scholar

- Research which is freely available for redistribution 